\title{
Fabrication of Friction Stir Processed Al-Ni Particulate Composite and Its Impression Creep Behaviour
}

\author{
Prakrathi Sampath, Vineeth Krishna Parangodath, \\ Kota Rajendra Udupa, and Udaya Bhat Kuruveri \\ Department of Metallurgical and Materials Engineering, NITK, Surathkal 575025, India \\ Correspondence should be addressed to Udaya Bhat Kuruveri; udayabhatk@gmail.com
}

Received 6 September 2014; Revised 10 January 2015; Accepted 11 January 2015

Academic Editor: Hui Shen Shen

Copyright (c) 2015 Prakrathi Sampath et al. This is an open access article distributed under the Creative Commons Attribution License, which permits unrestricted use, distribution, and reproduction in any medium, provided the original work is properly cited.

\begin{abstract}
Nickel powders were troweled on roughened Al base plate using a friction tool made from tool steel. Friction stir processing (FSP) was carried out using a load of $8 \mathrm{kN}$ and with a tool rotation speed of $800 \mathrm{rpm}$ and thus a surface composite was processed. Processed samples were characterized for revealing the microstructural features. SEM and XRD analysis revealed the presence of fine Ni particles in the stir zone which lead to a significant increase in hardness. Using the "refined energy model," the maximum temperature developed within the processed zone was estimated and found to be around $275^{\circ} \mathrm{C}$. Impression creep behaviour was assessed on both the base metal and processed zone at the temperature of 30,100 , and $200^{\circ} \mathrm{C}$. Creep curves were generated and steady state creep rate (SSCR) values were found out to determine the activation energy. It is observed that friction stirred regions record higher creep rate values compared to the base metal. Estimated activation energy is in the range of 6 to $16 \mathrm{~kJ} / \mathrm{mol}$. Activation energy is marginally lower in the base metal compared to friction stir processed region.
\end{abstract}

\section{Introduction}

Aluminium is the second most plentiful metallic element on earth and it is well suited for many of the engineering applications due to its light weight, appearance, mechanical properties, and ease of fabrication. However, pure $\mathrm{Al}$ is extremely poor in strength and hardness and it is one of the major limitations as far as the end application is concerned. There are many established ways to improve the strength and hardness of Al. A few of them are precipitation hardening, dispersion hardening, and composite hardening [1] These hardening processes also limit some other desired properties like formability and weldability. Further, they may also involve additional expenditure in the form of use of costly alloying elements and additional processing steps. An alternative approach is to convert only the surface of the component as a particle dispersed composite, without altering the bulk. Friction stir processing is a method suitable for converting surface of a component in to a composite.

Friction stir processing (FSP) is a thermomechanical working process developed on the concept of friction stir welding (FSW) $[2,3]$. In this process, the local composition and properties of a material can be modified without changing the bulk property of the same. For this reason, FSP is considered as one of the techniques of surface engineering in which the surface property can be modified according to the need of the designer. This process consists of a nonconsumable rotating tool with specially designed pin and shoulder, inserted onto the surface of the material and then moved and simultaneously rotated with choice of the speed under the predetermined load [4]. The primary functions of nonconsumable rotating tool are (i) to heat the specimen in the localized zone and (ii) to move and transport the materials within the processing zone (iii) to facilitate mixing up of externally added material to produce a composite material within the processed zone. The material flow associated with stirring and plastic deformation facilitates distribution of second phase particles. As a result, the stirred zone becomes a metal matrix composite with improved hardness and wear resistance [5]. The movement of softened material along and around the moving, rotating pin can promote nonequilibrium metallurgical events at the localized subsurface volume of the 


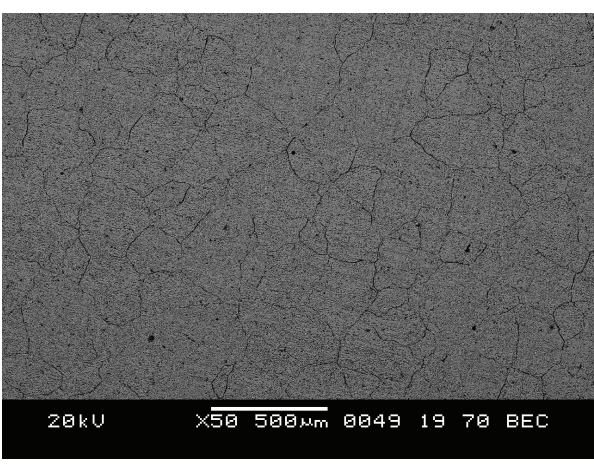

(a)

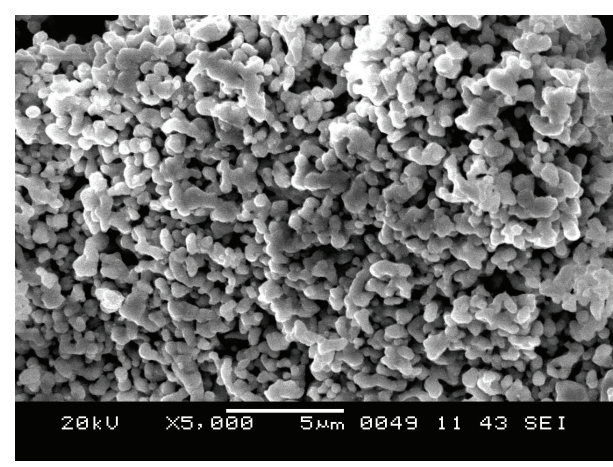

(b)

FIgURE 1: Microstructure of the base metal Al (a), initial morphology of nickel powders used for friction stir processing (b).

material. Because of this, sometimes friction stir processing is considered as a nonequilibrium materials processing.

Composite fabrication using friction stir processing route is reviewed by Arora et al. [6]. Surface engineering by FSP of Al with Ni powder is an interesting area [7-9], because it can give rise to many important phases which are stable at high temperature $[5,10-12]$.

There are a few investigations focusing on producing metal (matrix) metal (reinforcement) composite using friction stir processing route. Yadav and Bauri [13] reported the dispersion of nickel in $\mathrm{Al}$ alloy using FSP route and they observed no detectable aluminides in the friction stir processed zone. Ke et al. [14] reported in situ formation of $\mathrm{Al}_{3} \mathrm{Ni}$ intermetallics during friction stirring of $\mathrm{Al}$ substrate with nickel powder. They also reported formation of $\mathrm{Al}_{3} \mathrm{Ni}$ and $\mathrm{Al}_{3} \mathrm{Ni}_{2}$ after heat treatment. Composite also consisted of some amount of unreacted nickel powders. Using FSP route, Qian et al. [15, 16] produced $\mathrm{Al}-\mathrm{Al}_{3} \mathrm{Ni}$ in situ composites and this composite had better hardness and tensile properties compared to Al substrate alone.

Impression creep experiment is an important method of mechanical characterization of surface composites [17]. It can be used to estimate mechanical properties of a small restricted volume of the material (like surface composite) at various temperature levels. The method takes smaller time duration for the test. The temperature and stress dependency of creep rate could be obtained with minimum number of samples. This method is applicable to assessing the creep behavior of the parent metal and processed zone independently $[17,18]$.

An attempt is being made in the present investigation to assess the creep behavior of friction stirred Al with nickel powder processed with $8 \mathrm{kN}$ load at different tip rotation speed of $800 \mathrm{rpm}$. The processing parameters are entirely different compared to those reported earlier in reference [19]. Microstructural features and mechanical properties of FSP Al-Ni composite with $10 \mathrm{kN}$ normal force and $1200 \mathrm{rpm}$ are reported in [19]. Reduction in normal load and tool rotation speed is expected to alter the severity of the stirring, microstructural features, and mechanical properties.

\section{Experimental Details}

Friction stir processing is carried out on the commercial pure Al plate of $5 \mathrm{~mm}$ thickness. Base metal has relatively large grains (average grain size $\sim 130 \mu \mathrm{m}$ ) without the presence of any second phase particles. Initially, the substrate surface is made rough by a friction stir pass without any powder addition. Electrolytic nickel powder is mixed with methanol to get a paste consistency and is applied to rough substrate. Coverage of the powder is approximately $1 \mathrm{~g} / \mathrm{cm}^{2}$ of the sample. The microstructure of Al base metal and morphology of the nickel powder used are given in Figures 1(a) and 1(b), respectively. The substrate along with the powder is dried and used for friction stir processing. For friction stir processing, a friction tool made from heat treated tool steel is used. Dimensions of the tool are shoulder diameter $10 \mathrm{~mm}$, pin diameter $6 \mathrm{~mm}$, and pin depth $3 \mathrm{~mm}$. The FSP process parameters used are following: tool rotation speed $-800 \mathrm{rpm}$, tool travel speed $-0.3 \mathrm{~mm} / \mathrm{s}$, and axial force $-8 \mathrm{kN}$.

Using a precision sample cutting machine, the specimen is cut across the plate in the direction perpendicular to that of the run. The cut samples are polished using standard metallographic techniques and etched to reveal the metallurgical structure of the processed material. Macrostructure and microstructures are studied using scanning electron microscope (SEM, JEOL make, Model 6480 LA) with the attachment of EDS. For imaging and EDS analysis an accelerating voltage of $20 \mathrm{kV}$ is used. X-ray diffractometer (JEOL make, $\mathrm{Cu} \mathrm{K} \alpha$ radiation) is used to analyze the phases present in the materials.

The mechanical characterization of the processed zone and base metal is carried out using hardness and impression creep tests. Hardness test is conducted at different locations using microhardness tester (Make: Shimadzu, model: HMV G20ST, Load: $50 \mathrm{~g}$ ). Impression creep tests are carried out, both at friction stir zone (FSZ) and base metal zone (BMZ) using a tungsten carbide indentor. Figure 2 shows a sketch of tungsten carbide indentor used for impression creep experiments. During experiments, the indentor is made to penetrate 


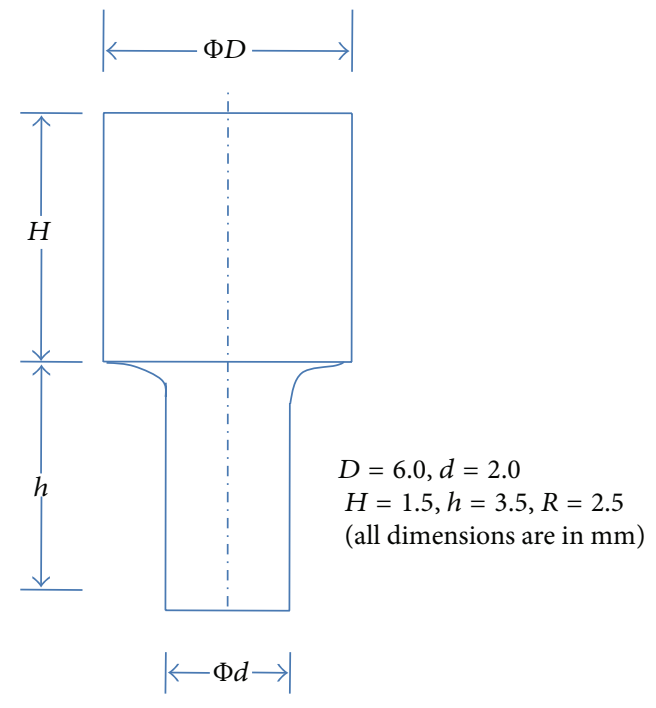

FIGURE 2: Dimensions of the tungsten carbide indentor used for impression creep experiments.

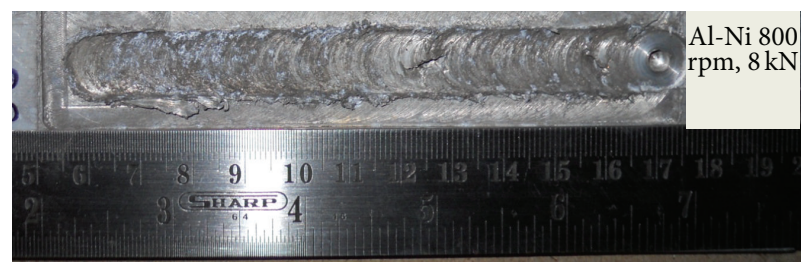

FIgURE 3: Top view of friction stir processed Al-Ni at load of $8 \mathrm{kN}$ with rotation speed of $800 \mathrm{rpm}$.

the sample at either FSZ or BMZ. A normal load of $5 \mathrm{~kg}$ is used during the impression test. On a two-millimeter diameter contact area this generates a stress of about $15.6 \mathrm{MPa}$. This stress value is smaller compared to yield strength of the aluminum [20]. During impression creep tests, the depth of the penetration of the indentor into the specimen is measured continuously using a linear variable differential transducer (LVDT). Impression creep tests are carried out for the duration of 180 minutes and it is believed that this time is sufficient to attain steady state creep conditions. Using this data a creep curve (i.e., plot of impression depth versus time) is drawn. The creep experiments are conducted at various temperatures, namely, $30^{\circ} \mathrm{C}, 100^{\circ} \mathrm{C}$, and $200^{\circ} \mathrm{C}$. They are used for estimating the activation energy for creep and understanding the creep mechanism. The maximum test temperature is slightly less than half of the absolute melting temperature of pure $\mathrm{Al}\left(193^{\circ} \mathrm{C}\right)$.

\section{Results and Discussion}

3.1. Characterization of Friction Stir Zone. Figure 3 shows top view of the friction stir processed sample and it shows characteristic marks of the friction stir processing. Morphological features are uniform throughout the length indicating that steady state conditions are attained during friction stir processing. Figure 4 shows a macroveiw of the processed zone

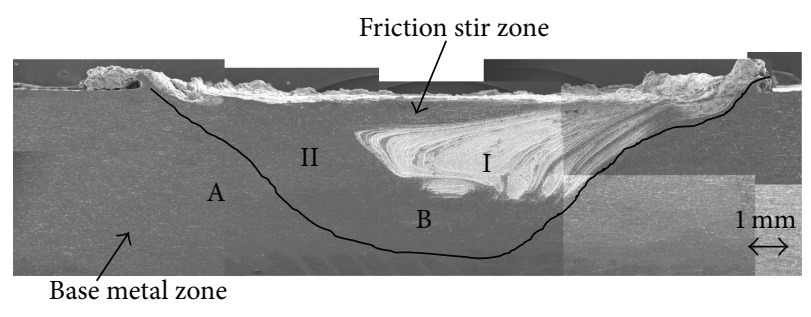

Figure 4: The macroview along perpendicular direction to the friction stir processing direction. It reveals two distinct regions: (A) base metal zone and (B) stir processed zone.

obtained after cutting the sample perpendicular to processed zone, polishing the cut section using standard metallographic techniques and etching to reveal the macrostructure (etchant used: Poulton's reagent; composition: $12 \mathrm{~mL}$ concentrated hydrochloric acid $+6 \mathrm{~mL}$ concentrated nitric acid $+1 \mathrm{~mL}$ $48 \%$ hydrofluoric acid $+1 \mathrm{~mL}$ distilled water). Figure 4 clearly distinguishes FSZ and BMZ. FSZ is wider at the top and became narrower in the depth direction. The depth is much greater than the pin length used (i.e., $3 \mathrm{~mm}$ ). Similar morphology during friction stir processing is reported in the literature by Kwon et al. [21], Oh-Ishi and McNelley [22], Leitão et al. [23], and Cui et al. [24].

In the present investigation it is found that the quality of nugget is good; there are no defects like porosity, inclusions, blow holes, or lack of bonding. The depth of the nugget is around $4.5 \mathrm{~mm}$, width at the top is about $20 \mathrm{~mm}$, and area of cross section of nugget is $48 \mathrm{~mm}^{2}$. The friction stir zone (FSZ) has two clearly visible regions: one with onion-ring-like morphology (referred to as region I) and remaining portion in FSZ is region II. The FSZ can be thought of as the result of overlapping of material flow due to shoulder and pin. In the case of friction stir welding, the tool driven material flow is classified into shoulder driven material flow and pin driven material flow $[25,26]$. Since tool features are kept similar, even in FSP, two types of friction driven material flow are expected to take place and they merge to form a FSZ. The tool geometry, axial force, tool rotation speed, traverse speed, and tool tilt angle are important process parameters which decide the heat input and material flow and in turn the quality of FSZ $[2,27,28]$. The temperature will be maximum at the tool pin-substrate interface and it drops being moved away from the interface. Depending on the temperature and plastic flow behaviour of the material, a section of the material close to tool flows. The volume of the material in this section is "action volume." Material flow is an important reason for promoting mixing of powder. Material enters from the retreading side in to the action volume and rotates at the back of the tool. Fratini et al. [29] reported that the tool rotation drives the material from the retreating side to advancing side and the flux is intense at the back of the tool, near the shoulder. The macrostructure shows that more material flows towards the advancing side near the shoulder. This is due to confinement of the transferred material with the processing cavity. When the tool is traversed, the material in the leading edge flows via retreating side to the trailing edge. This is continuous 


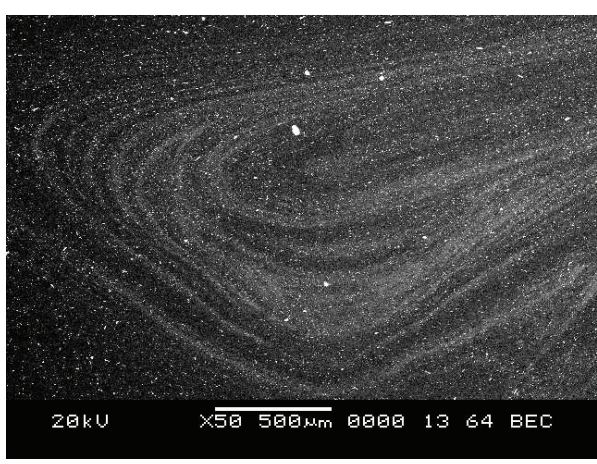

(a)

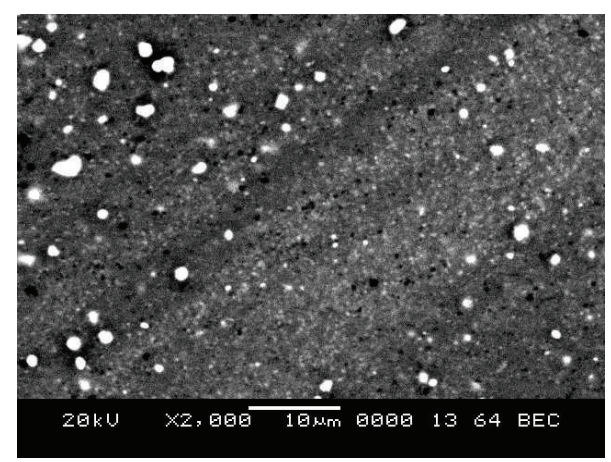

(b)

FIGURE 5: Microstructural features in region I. (a) Flow bands are visible; (b) distribution of second phase particles is presented.

and helps in filling the space created in the trailing edge. During this transfer process, the plasticized material flows between the tool and the relatively colder base material. The material flow at the top occurs by the sliding action of tool shoulder over the pin driven material $[27,28]$. When axial force exceeds a critical value, the flow becomes intense. It is responsible for shoulder driven flow.

The macrostructure shown in Figure 4 exhibits onionring-like structure with in FSZ. Formation of onion ring is a geometric effect. Semicylindrical sheets of material are extruded between friction tool and substrate material, during each rotation of the tool. During tool rotation, with axial force, the pin-driven material interacts with the shoulder at the retreating side. Material, which is flowing, carries minute microstructural and flow details. Depending on the magnitudes of the pin driven and shoulder driven flow, complex lamellar or vortex-like patterns are formed. They are referred to as onion-ring pattern. The material within this region is highly intercalated, consisting of layers of materials which can be easily macroetched $[27,30]$. Presence of second element particles increases the tendency for differential flow behavior, which in turn increases the contrast.

3.2. Mixing of Particles during Friction Stirring. In this particular composite, $\mathrm{Ni}$ is acting as particulate reinforcement and $\mathrm{Al}$ is the ductile matrix. From performance angle, it is desired that the nickel particles are uniformly and finely distributed in the $\mathrm{Al}$ matrix. SEM photomicrographs are taken at appropriate magnifications to investigate the particles' size and their distribution. Figure 5(a) shows a low magnification micrograph from region I. Figure 5(b) is a magnified microstructure from Figure 5(a). Similarly, Figures 6(a) and 6(b) show a low and high magnification micrograph from the region marked as II in the macroview presented in Figure 4. Comparing Figures 5(b) and 6(b), we see a clear difference in the size of particles and their distribution. The particles shown in Figure 5(b) (region I in FSZ) are finer and closely spaced compared to particles in Figure 6(b). Region I is towards retreading side in the FSZ. This also indicates that stirring action is more severe in region I compared to that in region II. Several researchers have suggested that there is a difference in the metal flow behaviour between the tool retreating sides (RS) and advancing side (AS) [25, 31]. Hence, it is likely that these microstructural differences resulted from the different flow behaviour on both sides.

Figure 7 shows XRD plot of the FSP nugget. The plot shows that nugget has the presence of $\mathrm{Al}$ and $\mathrm{Ni}$. There are no detectable intermetallics of $\mathrm{Al}$ and $\mathrm{Ni}$. The microstructure features and XRD plot confirm the fact that the weld nugget consists of $\mathrm{Al}$ and $\mathrm{Ni}$. $\mathrm{Ni}$ is dispersed as fine particles in $\mathrm{Al}$ matrix. It is clear that the stirring conditions are not severe enough to facilitate the formation of $\mathrm{Al}-\mathrm{Ni}$ intermetallics. It is reported that nature of interface between the matrix and reinforcement is important in deciding mechanical properties [26]. From Figures 5(b) and 6(b), we see that $\mathrm{Al}$ matrix-Ni particle interface is good, without any visible separation. Similar features are observed by Yadav and Bauri [13]. A good interface is very essential to strengthen the $\mathrm{Al}$ and to reduce the dislocation movement. There are few investigations reporting formation of $\mathrm{Al}-\mathrm{Ni}$ intermetallics during FSP. Prakrathi et al. [19] and Qian et al. [15] reported formation of $\mathrm{Al}_{3} \mathrm{Ni}$ by in situ reaction during FSP of $\mathrm{Al}$ with Ni particles under different stirring conditions.

During FSP, Ni particles disintegrate due to severe deformation and high temperature. Severe plastic flow with tool rotation causes fragmentation of the original $\mathrm{Ni}$ particles. Yadav and Bauri [13] and Fujii et al. [32] discussed how rotation speed influences the plastic flow and the heat input. As rotation speed increases, particles are reduced due to stirring effect. Material rotation in the weldment and stirring effect ensures a contamination-free surface and facilitates atom to atom contact and this promotes a good particlematrix interface.

3.3. Estimation of Nugget Temperature. In friction stir processing, the heat is generated by the friction between the tool and the work piece, as well as a result of the plastic deformation of the work piece [33]. An attempt is made in the present work to determine the energy generated and maximum temperature obtained within the processed zone of the nugget during FSP, using a "refined energy based model." Though the model is generated for friction stir welding $[34,35]$, the same can be used for friction stir processing without any modification. The values of parameters used for 


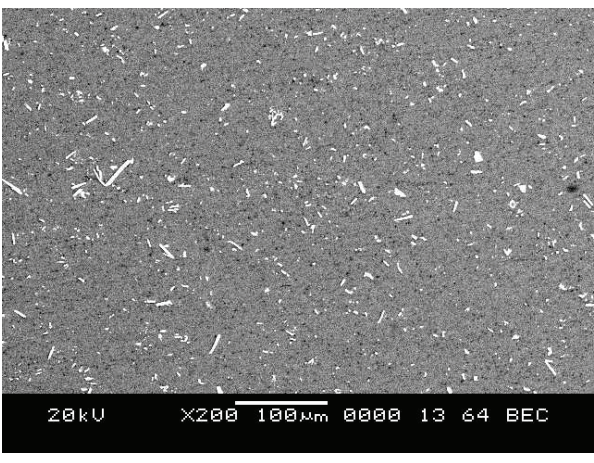

(a)

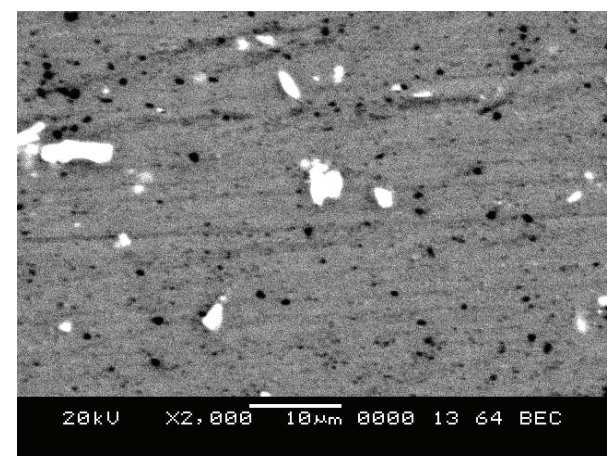

(b)

FIGURE 6: Microstructural features in region II in Figure 4. (a) Low magnification micrograph showing shape and distribution of the particles. (b) High magnification micrograph showing microporosities.

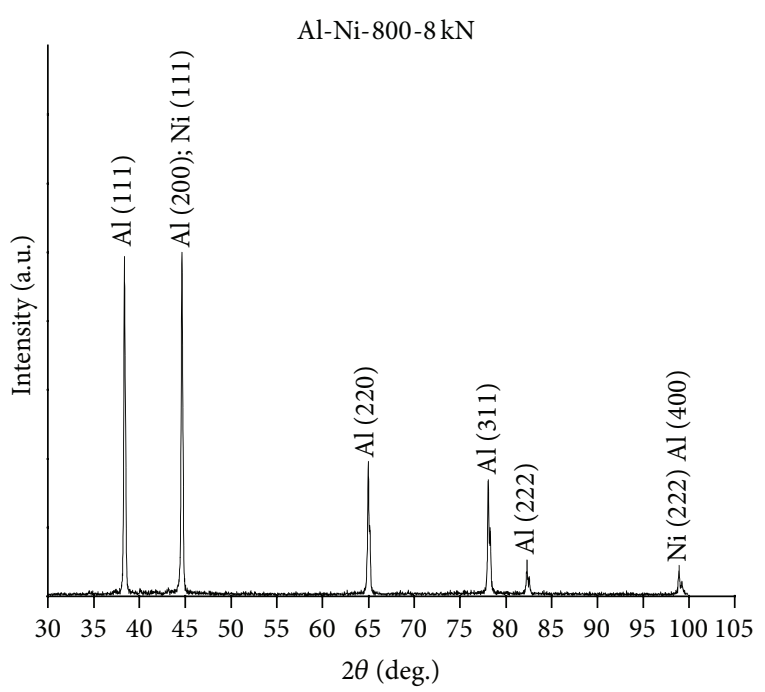

FIGURE 7: XRD plot of the FSZ showing Al and Ni particles. No visible indication of Al-Ni intermetallic compounds.

calculation of total power, effective energy, and maximum temperature generated within the processed zone of friction stirred samples are recorded in Table 1 . It is found that the maximum temperature attained is around $548^{\circ} \mathrm{K}\left(275^{\circ} \mathrm{C}\right)$ for the conditions under which stirring is carried out in the present work.

Kwon et al. [21] measured temperature during friction stir processing of $\mathrm{Al}$ and found that the peak temperature is a strong function of tool rotation speed. As reported by them, at $560 \mathrm{rpm}$, the maximum temperature measured is $200^{\circ} \mathrm{C}$. Use of a higher tool rotation speed will lead to higher peak temperature and the temperature is sufficient to promote recrystallisation [21]. Mishra and $\mathrm{Ma}$ [2] have reported a temperature of $550^{\circ} \mathrm{C}$ during $\mathrm{FSW}$ of $5083 \mathrm{Al}$ alloy, with high tool rotation speed. Mishra et al. [36] reported a peak temperature of $480^{\circ} \mathrm{C}$, in the case of friction stir welding of $6061 \mathrm{Al}$ alloy and $500^{\circ} \mathrm{C}$ in the case of friction stir welding of $2024 \mathrm{Al}$ alloy. They have used a triflute tool.
TABLE 1: Material and processing parameters used for calculation of total power, effective energy, and maximum temperature generated within the processed zone of friction stirred sample.

\begin{tabular}{|c|c|c|}
\hline Sl. number & Parameter & Value \\
\hline 1 & Shoulder radius $r_{o}(\mathrm{~m})$ & $5.00 E-03$ \\
\hline 2 & Pin radius $r_{i}(\mathrm{~m})$ & $1.50 E-03$ \\
\hline 3 & Pin height, $h(\mathrm{~m})$ & $3.00 E-03$ \\
\hline 4 & Co-efficient of friction, $\mu$ & 0.45 \\
\hline 5 & Tool translational velocity, $V_{o}(\mathrm{~m} / \mathrm{s})$ & $3.00 E-04$ \\
\hline 6 & Scale factor $s$ & 1 \\
\hline 7 & Effective strain, $\varepsilon_{e}$ & 6 \\
\hline 8 & Strength coefficient, $K$ & 690 \\
\hline 9 & Strain hardening exponent, $n$ & 0.16 \\
\hline 10 & Effective stress, $\sigma_{e}$ & 919.08 \\
\hline 11 & Thickness of the work piece, $t(\mathrm{~m})$ & $6.00 E-03$ \\
\hline 12 & Solidus temperature, $T_{s}(\mathrm{~K})$ & 933 \\
\hline 13 & Compressive force, $F(\mathrm{kN})$ & 8 \\
\hline 14 & Tool rotational speed, $\omega(\mathrm{rpm})$ & 800 \\
\hline 15 & $\begin{array}{l}\text { Energy generated due to plastic } \\
\text { deformation, } E_{P}(\mathrm{~N})\end{array}$ & $4.96 E-02$ \\
\hline 16 & Torque due to friction, $T_{f}(\mathrm{Nm})$ & 13.94 \\
\hline 17 & $\begin{array}{l}\text { Energy generated per unit length of } \\
\text { the weld, } E_{f}(\mathrm{kN})\end{array}$ & 619.73 \\
\hline 18 & $\begin{array}{l}\text { Power generated due to friction, } \\
P_{f}(\mathrm{Nm} / \mathrm{s})\end{array}$ & 185.92 \\
\hline 19 & Total energy, $E(\mathrm{kN})$ & 619.73 \\
\hline 20 & Total power, $P(\mathrm{Nm} / \mathrm{s})$ & $1.86 E+02$ \\
\hline 21 & Effective energy, $E_{\text {eff }}(\mathrm{kN})$ & 309.86 \\
\hline 22 & Maximum temperature, $T_{\max }(\mathrm{K})$ & 548.00 \\
\hline
\end{tabular}

3.4. Hardness Profile. Figure 8 shows hardness profiles along two lines over the FSZ. Line 1 shows variation of hardness at a depth of $0.5 \mathrm{~mm}$ from the top surface, measured over an equidistance of $0.5 \mathrm{~mm}$. Similarly, line 2 shows hardness variation at a depth of $1.5 \mathrm{~mm}$ from the top surface. The hardness profiles reveal two regions in the nugget zone: 

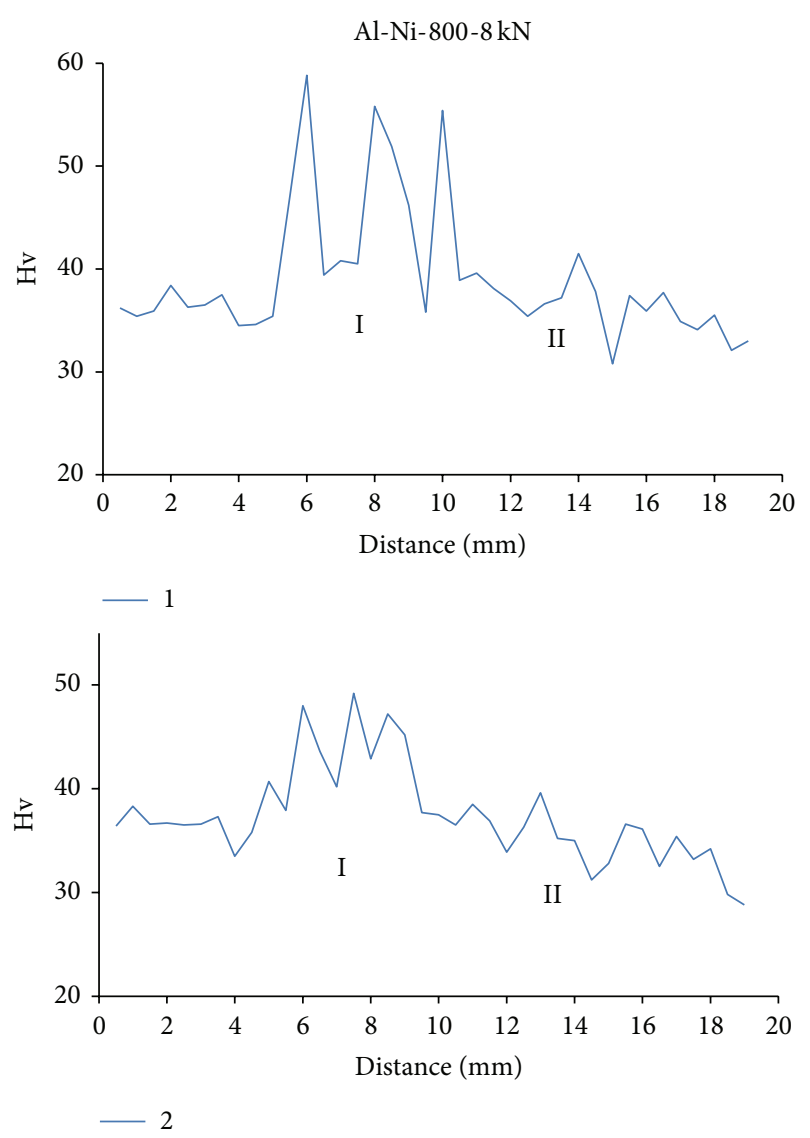

Figure 8: Hardness profile along two depths in the FSZ. Line 1: $0.5 \mathrm{~mm}$ depth from the top and line $2: 1.5 \mathrm{~mm}$ depth from the top.

region I in which hardness values fluctuate highly and region II in which hardness values fluctuate mildly around an average value. In line 1 , peak hardness is about $58 \mathrm{Hv}$ against a minimum hardness of $40 \mathrm{Hv}$. In line 2 , the peak value is $49 \mathrm{Hv}$ against a minimum value of $40 \mathrm{Hv}$. In region II of FSZ, the increase in hardness is marginal $(\sim 10 \%)$. The values are consistent with the extent of reinforcement as seen in Figures 5(b) and 6(b). In region I, the extent of particle reinforcement is higher and the spacing between the particles is smaller. Both features promote strengthening by particles. The material flow and particle entrapment are not homogeneous as revealed in flow lines. This may be the cause of fluctuations in hardness. In region II, the extent of particle reinforcement is smaller and also the amount of defect (pores) is larger. Because of these features, observed hardness improvement is smaller compared to region I.

The literature has recorded a mixed trend as far as variation of hardness during friction processing is concerned. Many researchers have reported a drop in the hardness after friction stirring $[37,38]$. In contrast to that, Kwon et al. [21] reported $37 \%$ increase in the hardness compared to the base metal and attributed that to very small recrystallised grains in the FSZ. Ke et al. [14] produced Al-Ni intermetallic composite by friction stir processing and they reported a hardness value of $53 \mathrm{Hv}$ in the composite against $37 \mathrm{Hv}$ in the friction

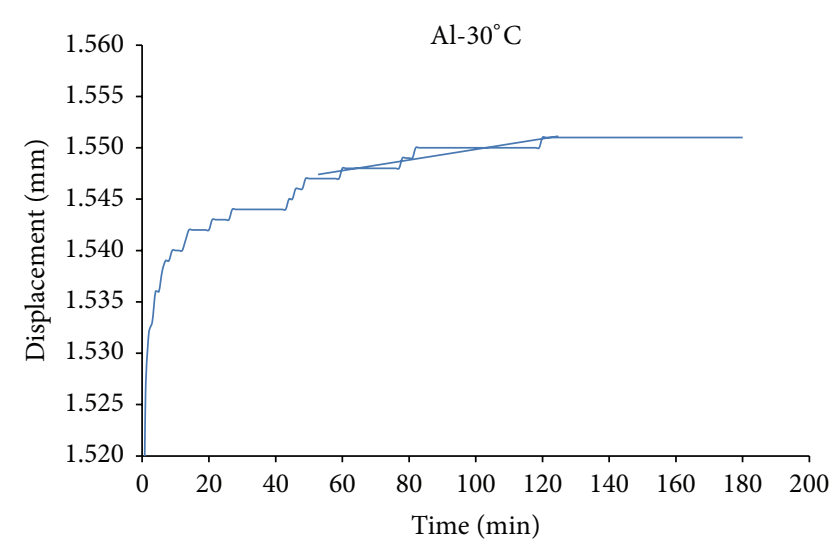

FIGURE 9: A typical impression depth versus time profile in $\mathrm{Al}$ base metal at $30^{\circ} \mathrm{C}$.

stir processed Al alloy (without reinforcement). Yadav and Bauri [13] reported a hardness value of $50 \mathrm{Hv}$ in the Al-Ni composite produced by friction stir processing of $\mathrm{Al}$ which had a hardness value of $29 \mathrm{Hv}$. In the present study, increase in hardness is attributed to combined effect of fine particles and refinement of grains in the matrix. Value of the hardness is not found to be constant and it is attributed to presence of different microstructures at different locations in the stir zone. Complex material flow pattern in the processing zone generates a gradient in temperature, strain, and strain rate across the stir zone and it leads to different microstructures at different locations in the stir zone. Qian et al. [15] reported that, for commercial pure $\mathrm{Al}$, friction stirring without $\mathrm{Ni}$ addition has no effect on the microhardness. Significant improvement in microhardness is possible with the addition of $\mathrm{Ni}$ particles.

3.5. Impression Creep Behaviour. In impression creep experiments, a predetermined load is applied on the indentor, positioned at either friction stir zone or base metal zone in the sample. The penetration depth is measured continuously as a function of time and using this data a plot of penetration depth versus time is drawn. A typical impression depth versus time curve generated for base metal at room temperature $\left(30^{\circ} \mathrm{C}\right)$ with a constant load of $5 \mathrm{~kg}$ is presented in Figure 9. Such depth versus time curves is generated for base metal and friction stir zones at room temperature of $\left(30^{\circ} \mathrm{C}\right), 100^{\circ} \mathrm{C}$, $150^{\circ} \mathrm{C}$, and $200^{\circ} \mathrm{C}$ and is used in analysis. These curves are shown in Figures 10(a) and 10(b), for base metal and friction stir zone, respectively. For each curve, impression creep strain $(\varepsilon)$ is estimated at different instant of time, following the approach presented by Sastry [17]. These data are used for drawing creep strain versus time plots (i.e., creep curves). Using these creep profiles, steady state creep rates $\left(\varepsilon^{\prime}\right)$ are determined as follows:

$$
\begin{aligned}
\varepsilon & =\frac{\Delta l}{D}, \\
\varepsilon^{\prime} & =\frac{\Delta \varepsilon}{\Delta t},
\end{aligned}
$$

where $\Delta l$ is penetration depth, $D$ is diameter of the indenter, and $\Delta \varepsilon$ represents incremental creep strain in the secondary 


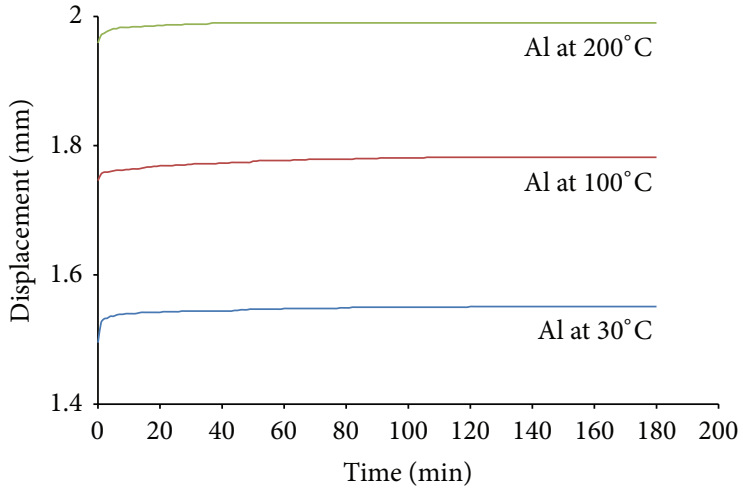

(a)

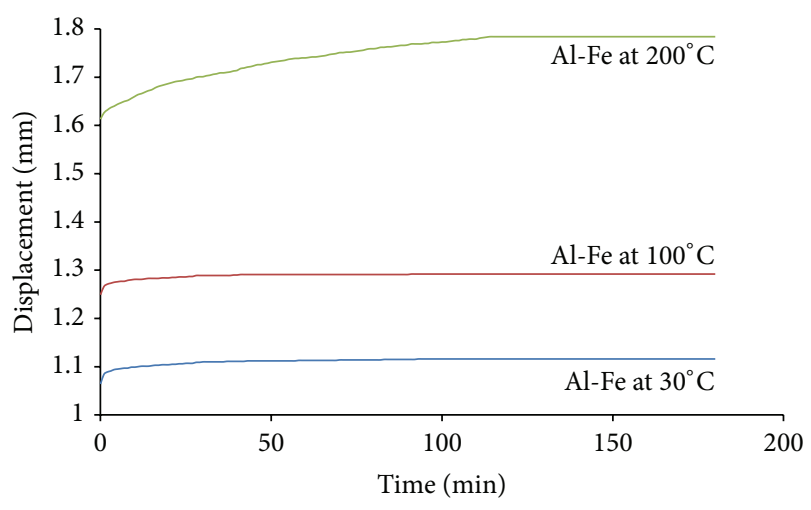

(b)

Figure 10: Displacement versus time plots for impression tests at $30^{\circ} \mathrm{C}, 100^{\circ} \mathrm{C}$, and $200^{\circ} \mathrm{C}$, (a) for $\mathrm{Al}$ base metal (b) FSP nugget.

TABLE 2: Steady state creep rate values at various temperatures for FSZ and BMZ.

\begin{tabular}{lcc}
\hline \multicolumn{3}{c}{ Steady state creep rate $\left(10^{-5} \mathrm{~min}^{-1}\right)$} \\
Temperature $\left({ }^{\circ} \mathrm{C}\right)$ & Base metal zone & Friction stirred zone \\
\hline 30 & 3.9 & 4.6 \\
100 & 8.3 & 15.2 \\
200 & 12.2 & 23.8 \\
\hline
\end{tabular}

TABLE 3: Activation energy (Q) values for FSZ and BMZ.

\begin{tabular}{lcc}
\hline \multicolumn{3}{c}{ Activation energy $(Q)$ values in $\mathrm{kJ} / \mathrm{mol}$} \\
Temperature $\left({ }^{\circ} \mathrm{C}\right)$ & Base metal zone & Friction stirred zone \\
\hline $30-100$ & 10 & 15.9 \\
$100-200$ & 5.8 & 6.6 \\
\hline
\end{tabular}

stage of the creep curve profile over the incremental time [17]. The values of steady state creep rates are estimated at different temperatures at both FSZ and BMZ. These values are presented in Table 2 and it shows that creep resistance of base metal zone is better than that of friction stir zone. Further, the creep resistance decreases or steady state creep rate increases as temperature is increased, for both BMZ and FSZ. Following observations could be made from the data presented in Table 2:

(i) At all test temperatures, the steady state creep rate is lower in friction stir zone compared to that in base metal zone.

(ii) For both FSZ and BMZ, the steady state creep rate increases exponentially with increase in temperature.

Using test temperature and corresponding steady state creep rate $\left(\varepsilon^{\prime}\right)$, activation energy $(Q)$ is estimated:

$$
Q=\frac{R \ln \left(\varepsilon_{1}^{\prime} / \varepsilon_{2}^{\prime}\right)}{\left(1 / T_{2}\right)-\left(1 / T_{1}\right)},
$$

where $\varepsilon_{1}^{\prime}$ and $\varepsilon_{2}^{\prime}$ are steady state creep rates at temperatures $T_{1}$ and $T_{2}$, respectively. Table 3 shows values of activation energy for the impression creep of the friction stirred zone and base metal. The value of activation energy is very small compared to the activation energy for movement of dislocations in $\mathrm{Al}$ as reported by Luthy et al. [39]. For high purity $\mathrm{Al}$, at lower temperatures $\left(<400^{\circ} \mathrm{K}\right)$ an activation energy in the range of $20 \mathrm{~kJ} / \mathrm{mol}$ is reported by Ishikawa et al. [40] and Ueda et al. [41]. For commercial purity $\mathrm{Al}$, an activation energy value $(Q)=25 \mathrm{~kJ} / \mathrm{mol}$ is reported by Shen et al. [42]. Also, a low activation energy, $Q=20-35 \mathrm{~kJ} / \mathrm{mol}$, under very low strain rate conditions $\left(<6 * 10^{-5} / \mathrm{min}\right)$ is reported [42]. They pointed that, in the case of pure metals with high stacking fault energy (HSFE), dislocation cross slip is a possible creep mechanism. It is pointed that creep behavior at low temperatures and very low strain rates depends on the grain size and impurity concentration [42]. The reported $Q=$ $25 \mathrm{~kJ} / \mathrm{mol}$ is for average grain size of $25 \mu \mathrm{m}$, for a commercial pure Al. Also, it is pointed that dislocations are getting generated at the grain boundary by "Frank Reed source" and they interact with the intragranular dislocations. Continuous generation of dislocations and their interactions with the inner dislocations promote dislocation cross slip and the fact that a large number of slip systems promote jog formation and help in strain accommodation [41]. This leads to plastic strain at low temperatures and low stress values. Ueda et al. [41] reported that, at a temperature of $473^{\circ} \mathrm{K}$, a normalized stress is $10^{-4}$ (approximately $\sim 7 \mathrm{MPa}$ ) which could produce a steady state creep rate of $10^{-6} /$ minutes. This value is slightly less than that in our results. The difference is attributed to use of higher level of stress. Also, in the friction stir zone, the SSCR is still higher and it is attributed to nonequilibrium nature in the FSP zone. Sherby and Taleff [43] reported that, at low stresses, dislocation glide and climb are the mode of plastic deformation and generally climb controls the rate. Fineness in the grain size promotes dislocation generation and the solute atoms or the second phase particle decides resistance for movement of dislocation. Carreño and Ruano [44] reported that addition of transition elements increases activation energy for creep deformation.

From the values for activation energy, it could be inferred that dislocation creep is the major mechanism of creep. So, 
activation energy for creep is decided by energy required to generate the dislocation and resistance offered by the matrix to the movement of dislocation. Friction stir processing has created largely a metastable condition in the zone. The thermodynamic instability increases as the speed of the processing is increased. This leads to a situation where huge number of dislocation can be readily moved by a small amount of thermal activation. For a similar reason process zone records higher rate of creep compared to Al base metal. Kwon et al. [21] reported that the FSZ has very fine recrystallised grains with very low dislocation density. As rotational speed increases, the temperature increases leading to growth of the recrystallised grains. FSP is an effective tool to reduce grain size in $\mathrm{Al}$ alloys via dynamic recrystallisation. A fine grain size in the range of 0.5 to $5 \mu \mathrm{m}$ in the recrystallisated zone by many investigators $[2,3,6]$. The submicron grain structure gets stabilized in presence of submicron sized particles. The fine particles in the matrix aid in the evolution of finer grain structure during thermomechanical processing through particle pinning. It also aids in material strengthening through grain boundary strengthening [6]. Yadav and Bauri [5] reported a final grain size of $7 \mu \mathrm{m}$ during FSP, with a relatively less normal force and slightly higher RPM. Also, FSP reduces both nickel particle and matrix grain size. Yazdipour et al. [45] reported the formation of nanograins due to dynamic recrystallisation. The size of the recrystallised grain is closely related to interaction of grain boundaries with second phase particles.

\section{Conclusions}

Following conclusions are drawn from this investigation.

(i) A surface composite on commercial pure $\mathrm{Al}$ is processed using friction stir processing route. The surface consists of fine nickel particles embedded in $\mathrm{Al}$ matrix.

(ii) Formation of friction stir zone can be explained using the concept of pin driven flow and shoulder driven flow.

(iii) During friction stir processing both particle size and matrix grain are reduced. Dynamic recrystallisation of the matrix is possible due to high plastic deformation and heat generated during processing.

(iv) Microstructure and particle distribution are nonhomogeneous and it is attributed to less severe processing conditions used (lower load and smaller tool rotation speed). This is reflected in the scattered microhardness values in the FSZ.

(v) Compared to base metal, friction stir zone recorded higher creep rate and, for both base metal and friction stirred region, creep rate increases with increase of temperature.

(vi) A low value of activation energy is observed and it is attributed to fine grain size and large amount of dislocation density in the processed zone. The value of activation energy is compared with the reported values.

\section{Conflict of Interests}

The authors declare that there is no conflict of interests regarding publication of this paper.

\section{Acknowledgments}

The authors gratefully acknowledge The Director, NITK Surathkal, for his continuous support for carrying out this work. They also acknowledge the help of Dr. G. Phanikumar and Dr. Raffi, IIT Madras, in carrying out friction stir processing work.

\section{References}

[1] M. F. Ashby and D. R. H. Zones, Engineering Materials, vol. 2, Butterworth-Heinemann, 2nd edition, 1998.

[2] R. S. Mishra and Z. Y. Ma, "Friction stir welding and processing," Materials Science and Engineering R: Reports, vol. 50, no. 1-2, pp. 1-78, 2005.

[3] R. S. Mishra, M. W. Mahoney, S. X. McFadden, N. A. Mara, and A. K. Mukherjee, "High strain rate superplasticity in a friction stir processed $7075 \mathrm{Al}$ alloy," Scripta Materialia, vol. 42, no. 2, pp. 163-168, 1999.

[4] R. S. Mishra, Z. Y. Ma, and I. Charit, "Friction stir processing: a novel technique for fabrication of surface composite," Materials Science and Engineering A, vol. 341, no. 1-2, pp. 307-310, 2003.

[5] D. Yadav and R. Bauri, "Nickel particle embedded aluminium matrix composite with high ductility," Materials Letters, vol. 64, no. 6, pp. 664-667, 2010.

[6] H. S. Arora, H. Singh, and B. K. Dhindaw, "Composite fabrication using friction stir processing-a review," International Journal of Advanced Manufacturing Technology, vol. 61, no. 912, pp. 1043-1055, 2012.

[7] Z. Zhang, E. Akiyama, Y. Watanabe, Y. Katada, and K. Tsuzaki, "Effect of $\alpha-\mathrm{Al} / \mathrm{Al}_{3} \mathrm{Ni}$ microstructure on the corrosion behaviour of Al-5.4 wt\% Ni alloy fabricated by equal-channel angular pressing," Corrosion Science, vol. 49, no. 7, pp. 29622972, 2007.

[8] C.-J. Song, Z.-M. Xu, and J.-G. Li, "In-situ $\mathrm{Al} / \mathrm{Al}_{3} \mathrm{Ni}$ functionally graded materials by electromagnetic separation method," Materials Science and Engineering: A, vol. 445-446, pp. 148-154, 2007.

[9] G. Gonzalez, A. Sagarzazu, D. Bonyuet, L. D’Angelo, and R. Villalba, "Solid state amorphisation in binary systems prepared by mechanical alloying," Journal of Alloys and Compounds, vol. 483, no. 1-2, pp. 289-297, 2009.

[10] T. P. D. Rajan, R. M. Pillai, and B. C. Pai, "Functionally graded $\mathrm{Al}-\mathrm{Al}_{3} \mathrm{Ni}$ in situ intermetallic composites: fabrication and microstructural characterization," Journal of Alloys and Compounds, vol. 453, no. 1-2, pp. L4-L7, 2008.

[11] B. S. B. Reddy, K. Rajasekhar, M. Venu, J. J. S. Dilip, S. Das, and K. Das, "Mechanical activation-assisted solid-state combustion synthesis of in situ aluminum matrix hybrid $\left(\mathrm{Al}_{3} \mathrm{Ni} / \mathrm{Al}_{2} \mathrm{O}_{3}\right)$ nanocomposites," Journal of Alloys and Compounds, vol. 465, no. 1-2, pp. 97-105, 2008.

[12] J. B. Fogagnolo, E. M. J. A. Pallone, D. R. Martin, C. S. Kiminami, C. Bolfarini, and W. J. Botta, "Processing of Al matrix composites reinforced with $\mathrm{Al}-\mathrm{Ni}$ compounds and $\mathrm{Al}_{2} \mathrm{O}_{3}$ by reactive milling and reactive sintering," Journal of Alloys and Compounds, vol. 471, no. 1-2, pp. 448-452, 2009. 
[13] D. Yadav and R. Bauri, "Processing, microstructure and mechanical properties of nickel particles embedded aluminium matrix composite," Materials Science and Engineering: A, vol. 528, no. 3, pp. 1326-1333, 2011.

[14] L. Ke, C. Huang, L. Xing, and K. Huang, "Al-Ni intermetallic composites produced in situ by friction stir processing," Journal of Alloys and Compounds, vol. 503, no. 2, pp. 494-499, 2010.

[15] J. Qian, J. Li, J. Xiong, F. Zhang, and X. Lin, "In situ synthesizing $\mathrm{Al}_{3} \mathrm{Ni}$ for fabrication of intermetallic-reinforced aluminum alloy composites by friction stir processing," Materials Science and Engineering A, vol. 550, pp. 279-285, 2012.

[16] C. J. Hsu, P. W. Kao, and N. J. Ho, "Intermetallic-reinforced aluminum matrix composites produced in situ by friction stir processing," Materials Letters, vol. 61, no. 6, pp. 1315-1318, 2007.

[17] D. H. Sastry, "Impression creep technique-an overview," Materials Science and Engineering A, vol. 409, no. 1-2, pp. 67-75, 2005.

[18] G. Sharma, R. V. Ramanujan, T. R. G. Kutty, and N. Prabhu, "Indentation creep studies of iron aluminide intermetallic alloy," Intermetallics, vol. 13, no. 1, pp. 47-53, 2005.

[19] S. Prakrathi, M. Ravikumar, K. R. Udupa, and K. U. Bhat, "Fabrication of hybrid surface composite through friction stir processing and its impression creep behaviour," ISRN Materials Science, vol. 2013, Article ID 541762, 6 pages, 2013.

[20] R. A. Higgins, Engineering Metallurgy, Arnold Publisher, New York, NY, USA, 6th edition, 1993.

[21] Y.-J. Kwon, I. Shigematsu, and N. Saito, "Production of ultra-fine grained aluminum alloy using friction stir process," Materials Transactions, vol. 44, no. 7, pp. 1343-1350, 2003.

[22] K. Oh-Ishi and T. R. McNelley, "Microstructural modification of as-cast NiAl bronze by friction stir processing," Metallurgical and Materials Transactions A: Physical Metallurgy and Materials Science, vol. 35, no. 9, pp. 2951-2961, 2004.

[23] C. Leitão, A. Loureiro, D. M. Rodrigues, P. Vilaça, and R. M. Leal, "Material flow in heterogeneous friction stir welding of thin aluminium sheets: effect of shoulder geometry," Materials Science and Engineering A, vol. 498, no. 1-2, pp. 384-391, 2008.

[24] G. R. Cui, Z. Y. Ma, and S. X. Li, “The origin of non-uniform microstructure and its effects on the mechanical properties of a friction stir processed Al-Mg alloy," Acta Materialia, vol. 57, no. 19, pp. 5718-5729, 2009.

[25] A. P. Reynolds, "Visualisation of material flow in autogenous friction stir welds," Science and Technology of Welding and Joining, vol. 5, no. 2, pp. 120-124, 2000.

[26] S. C. Tjong and Z. Y. Ma, "Microstructural and mechanical characteristics of in situ metal matrix composites," Materials Science and Engineering R: Reports, vol. 29, no. 3, pp. 49-113, 2000.

[27] K. Kumar and S. V. Kailas, "The role of friction stir welding tool on material flow and weld formation," Materials Science and Engineering A, vol. 485, no. 1-2, pp. 367-374, 2008.

[28] Z. W. Chen, T. Pasang, and Y. Qi, "Shear flow and formation of Nugget zone during friction stir welding of aluminium alloy 5083-O," Materials Science and Engineering A, vol. 474, no. 1-2, pp. 312-316, 2008.

[29] L. Fratini, G. Buffa, D. Palmeri, J. Hua, and R. Shivpuri, "Material flow in FSW of AA7075-T6 butt joints: continuous dynamic recrystallization phenomena," Journal of Engineering Materials Technology, vol. 128, no. 3, pp. 428-435, 2006.

[30] L. E. Murr, "A review of FSW research on dissimilar metal and alloy systems," Journal of Materials Engineering and Performance, vol. 19, no. 8, pp. 1071-1089, 2010.
[31] K. Colligan, "Material flow behavior during friction stir welding of aluminum," Welding Journal, vol. 78, no. 7, pp. 229s-237s, 1999.

[32] H. Fujii, Y. G. Kim, T. Tsumura, T. Komazaki, and K. Nakata, "Estimation of material flow in stir zone during friction stir welding by distribution measurement of Si particles," Materials Transactions, vol. 47, no. 1, pp. 224-232, 2006.

[33] R. Nandan, T. DebRoy, and H. K. D. H. Bhadeshia, "Recent advances in friction-stir welding-process, weldment structure and properties," Progress in Materials Science, vol. 53, no. 6, pp. 980-1023, 2008.

[34] S. A. Emam and A. E. Domiaty, "A refined energy based model for friction stir welding," World Academy of Science, Engineering and Technology, vol. 29, pp. 1010-1016, 2009.

[35] C. Hamilton, S. Dymek, and A. Sommers, "A thermal model of friction stir welding in aluminum alloys," International Journal of Machine Tools and Manufacture, vol. 48, no. 10, pp. 1120-1130, 2008.

[36] R. S. Mishra, W. Murray, and T. Mahoney, Friction Stir welding and Processing, ASM International, 2007.

[37] L. E. Murr, G. Liu, and J. C. McCure, "Dynamic recrystallisation in friction stir welding of 1100 Aluminum," Journal of Materials Science Letters, vol. 16, pp. 1801-1803, 1997.

[38] S. Benavides, Y. Li, L. E. Murr, D. Brown, and J. C. McClure, "Low-temperature friction-stir welding of 2024 aluminum," Scripta Materialia, vol. 41, no. 8, pp. 809-815, 1999.

[39] H. Luthy, A. K. Miller, and O. D. Sherby, "The stress and temperature dependence of steady state flow at intermediate temperatures for pure polycrystalline Al," Acta Metallurgica, vol. 28, no. 2, pp. 169-178, 1980.

[40] K. Ishikawa, M. Maehara, and Y. Kobayashi, "Mechanical modeling and microstructural observation of pure aluminum crept under constant stress," Materials Science and Engineering A, vol. 322, no. 1-2, pp. 153-158, 2002.

[41] S. Ueda, T. Kameyama, T. Matsunaga, K. Kitazono, and E. Sato, "Re-examination of creep behaviour of high purity aluminium at low temperature," Journal of Physics, vol. 240, Article ID 012073, 2010

[42] J. Shen, S. Yamasaki, K.-I. Ikeda, S. Hata, and H. Nakashima, "Low-temperature creep at ultra-low strain rates in pure aluminum studied by a helicoid spring specimen technique," Materials Transactions, vol. 52, no. 7, pp. 1381-1387, 2011.

[43] O. D. Sherby and E. M. Taleff, "Influence of grain size, solute atoms and second-phase particles on creep behavior of polycrystalline solids," Materials Science and Engineering A, vol. 322, no. 1-2, pp. 89-99, 2002.

[44] F. Carreño and O. A. Ruano, "Influence of dispersoids on the creep behavior of dispersion strengthened aluminum materials," Revista de Metalurgia, vol. 33, no. 5, pp. 324-332, 1997.

[45] A. Yazdipour, M. A. Shafiei, and K. Dehghani, "Modeling the microstructural evolution and effect of cooling rate on the nanograins formed during the friction stir processing of Al5083," Materials Science and Engineering: A, vol. 527, no. 1-2, pp. 192-197, 2009. 

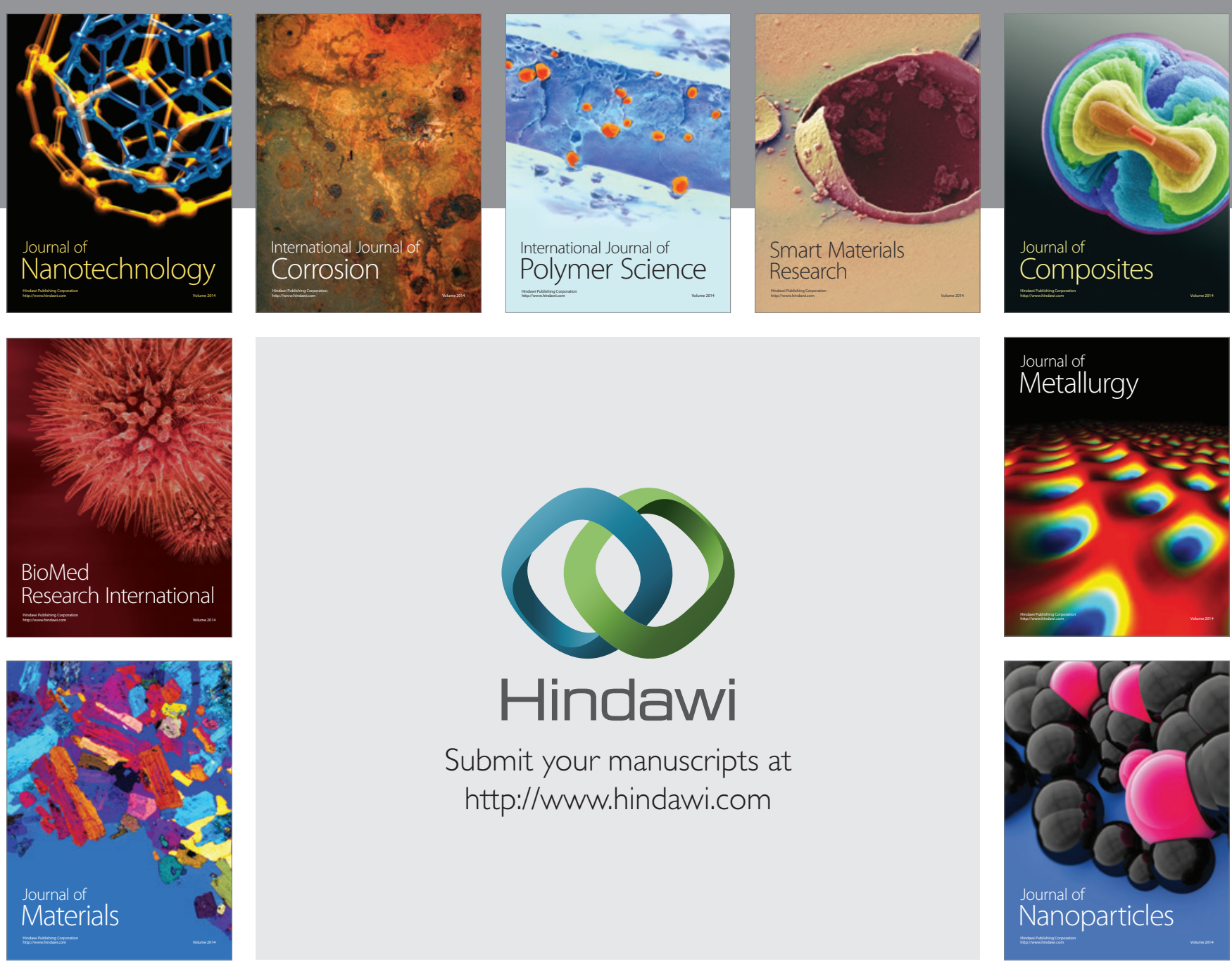

Submit your manuscripts at http://www.hindawi.com
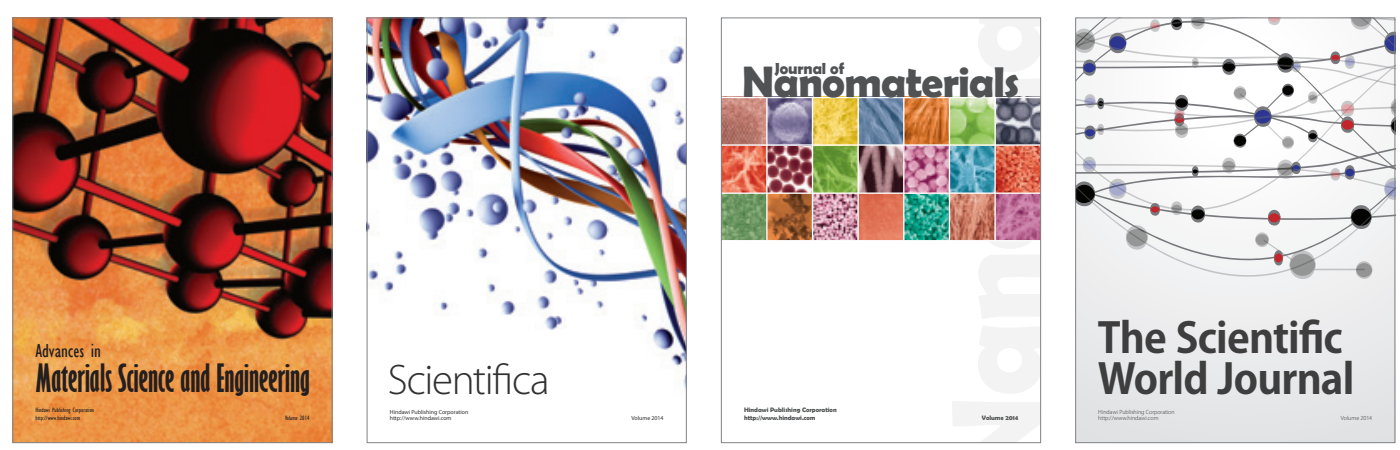

\section{The Scientific World Journal}
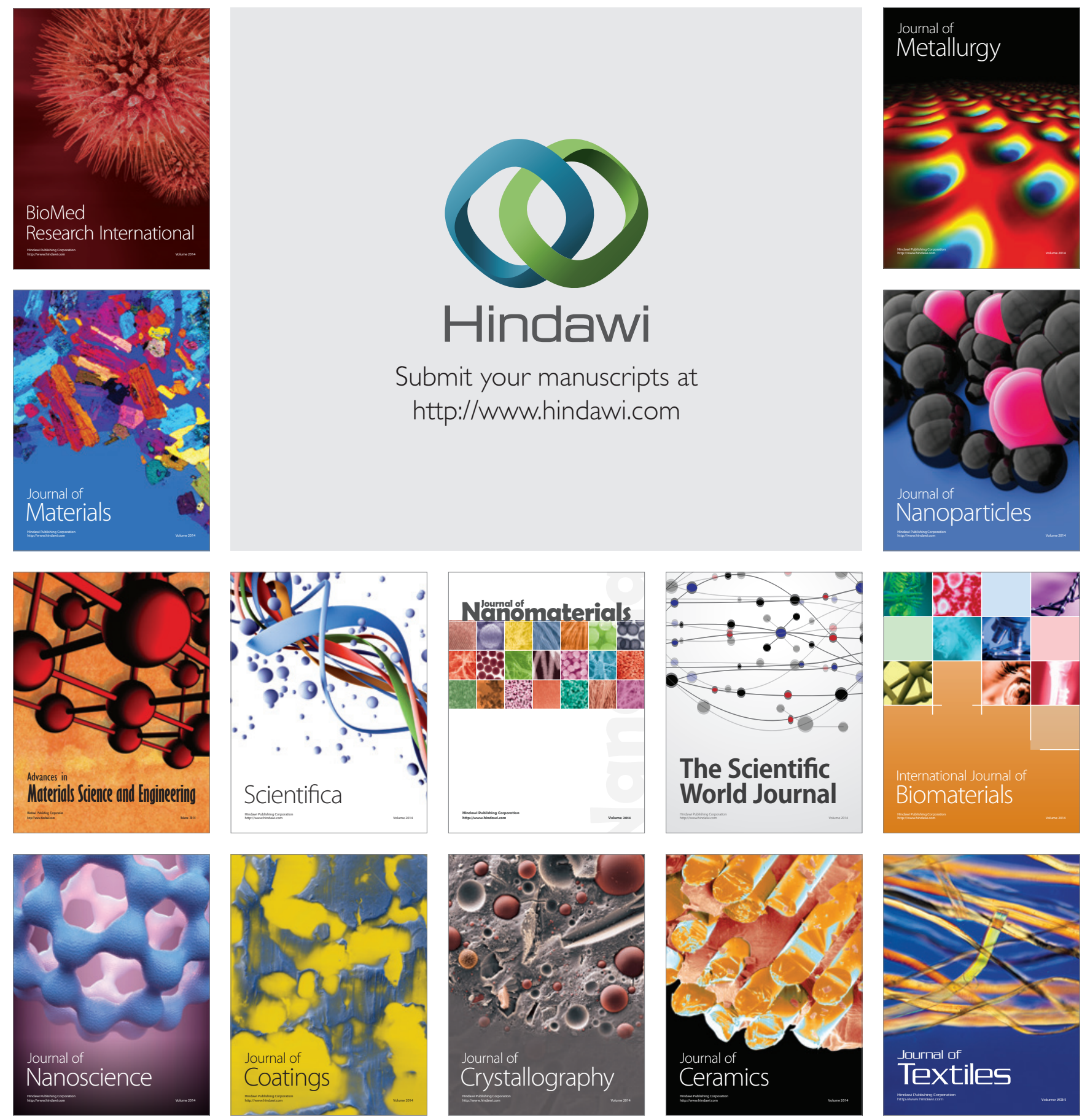